\title{
Gastroprotective effect of ranitidine bismuth citrate is associated with increased mucus bismuth concentration in rats
}

\author{
S Tanaka, P H Guth, G Paulsen, J D Kaunitz
}

\begin{abstract}
Background-Antisecretory and bismuth compounds protect the gastric mucosa from injury resulting from non-steroidal anti-inflammatory drugs.
\end{abstract}

Aim-To study the mechanism underlying the gastroprotective effects of ranitidine bismuth citrate (GG311) in rats.

Methods-Indomethacin rat injury model and in vivo microscopy in which acid output, surface cell intracellular $\mathbf{p H}\left(\mathbf{p H}_{\mathbf{i}}\right)$, gastric mucus gel thickness, and mucosal blood flow were measured simultaneously.

Results-In injury studies, GG311 dose dependently protected against severe injury induced by indomethacin $(60 \mathrm{mg} /$ $\mathrm{kg}$ subcutaneously). In in vivo microscopic studies, indomethacin significantly decreased mucus gel thickness and increased the initial rate of acidification of gastric surface cells when the superfusate pH was lowered from $7 \cdot 4$ to $1 \cdot 0$, and impaired $\mathrm{pH}_{\mathrm{i}}$ during acid exposure. Indomethacin had no effect on mucosal blood flow or acid output. GG311 alone had no effect on gel thickness, blood flow, or $\mathrm{pH}_{\mathbf{i}}$ homeostasis during acid exposure, but improved the initial acidification rate and $\mathrm{pH}_{\mathrm{i}}$ during superfusion with $\mathrm{pH} 1 \cdot 0$ solutions in the presence of indomethacin. In separate experiments, indomethacin pretreatment considerably increased gastric mucus bismuth concentrations in rats given GG311.

Conclusions-The gastroprotective effect of GG311 against indomethacin induced gastric injury is associated with high and prolonged gastric mucus bismuth concentrations, which may impair proton permeation across the mucus gel. (Gut 1996; 39: 164-171)

Keywords: stomach, intracellular $\mathrm{pH}$, ranitidine bismuth citrate, gastric mucus, proton diffusion, mucosal blood flow.

Bismuth salts protect the gastric mucosa from damage caused by non-steroidal anti-inflammatory drugs (NSAIDs) by a yet undefined mechanism. ${ }^{12}$ The most usual explanations advanced have suggested that the primary mode of action of bismuth on the gastric mucosal barrier is at the pre-epithelial level. ${ }^{3-5}$ Antisecretory compounds, such as $\mathrm{H}_{2}$ receptor antagonists, have also been shown to prevent duodenal ulcers in patients taking NSAIDs. ${ }^{67}$

Ranitidine bismuth citrate (GG311) is a novel drug that combines two compounds known to protect the gastric mucosa: an $\mathrm{H}_{2}$ receptor antagonist and a bismuth salt. This compound has been shown to prevent NSAID induced gastric ulcers in an animal model ${ }^{8}$ and in a clinical study. ${ }^{9}$ However, the mechanism by which GG311 protects gastric mucosa has not been clearly explained. The aim of this study is therefore to ascertain the effect of this novel compound on gastric defensive mechanisms, as determined with an established gastric corpus injury model induced by indomethacin, ${ }^{1011}$ and with a novel system developed in our laboratory that enables the gastric barrier function to be measured in vivo.

\section{Methods}

ANIMALS

Male Sprague-Dawley rats weighing 200-250 g were fasted overnight, but had free access to water. All studies were approved by the Animal Use Committee of the West Los Angeles Veterans Administration Medical Center.

ASSESSMENT OF GASTRIC MUCOSAL LESIONS Rats were killed in a carbon dioxide chamber, the abdomens opened, and the stomachs removed and opened along the greater curvature. Severe lesions were assessed according to previously described methods. ${ }^{11}$ The lesions were graded and scored by an observer who was unaware of the drugs administered as follows: petechial lesions $=1$, erosions less than 1 $\mathrm{mm}=2$, erosions between 1 and $2 \mathrm{~mm}=3$, erosions between 2 and $4 \mathrm{~mm}=4$, and erosions greater than $4 \mathrm{~mm}=$ actual length in $\mathrm{mm}$. The individual lesion scores in each rat were summed to provide a lesion score for each animal.

For histological evaluation, three strips of tissue were taken from across the entire posterior wall (parallel to the limiting ridge): (a) just below the limiting ridge, (b) the midcorpus, and (c) the distal-corpus. The severity of gastric mucosal injury was evaluated on the sections stained with haematoxylin and eosin using a modification of established criteria. ${ }^{12}$ Damage was graded as follows: surface mucous cell damage (surface damage); erosions down to, but not deeper than, the 
mucous neck cell area (superficial erosions); and erosions extending down into the parietal cell area (deep erosions). At least 100 glands were assessed in each specimen. The lesion score was calculated by multiplying the percentage of glands with no injury by 0 , the percentage with surface damage by 1 , the percentage with superficial erosions by 2 , and the percentage with deep lesions by 3 . The scores were then added and averaged among the three specimens.

\section{IN VIVO MICROSCOPIC MEASUREMENTS}

An in vivo microfluorometric technique, described in detail elsewhere, ${ }^{13-17}$ was used to measure intracellular $\mathrm{pH}\left(\mathrm{pH}_{\mathrm{i}}\right)$ and mucous gel thickness. The initial acidification rate was calculated from the fall of $\mathrm{pH}_{\mathrm{i}}$ during the first two minutes of acid exposure as described previously. ${ }^{14}$ Gastric mucosal blood flow was measured by laser-Doppler flowmetry, as a percentage of baseline, and acid secretion was measured by back titration. ${ }^{18}$ In brief, the technique entails microscopic observation of the gastric mucosa of an urethane anaesthetised rat under epifluorescent illumination. The mucosa is continuously superfused by means of a perfusion chamber. Carbon particles, placed on top of the mucus gel, delineate the mucus-luminal interface, ${ }^{19}$ enabling measurement of mucus gel thickness by up and down focusing. Intracellular $\mathrm{pH}$ is measured by a ratiometric technique using the trapped intracellular dye 5,6 carboxyfluorescein diacetate (CF). Image analysis is used to limit the area of interest for $\mathrm{pH}_{\mathrm{i}}$ measurements to two to three surface cells.

\section{MEASUREMENT OF MUCUS AND SERUM BISMUTH CONCENTRATION}

The bismuth concentration in gastroduodenal mucus was measured using a modification of the method of Slikerveer et al, ${ }^{20}$ with mucus collected according to the method of Muñoz et al. ${ }^{21}$ Gastric and duodenal mucus were gently scraped with a glass slide and weighed. Blood was collected by cardiac puncture. Mucus and serum were solubilised in $5 \mathrm{M}$ $\mathrm{HNO}_{3}$ for 12 hours at $70^{\circ} \mathrm{C}$. Water was then added for a final concentration of $0.5 \mathrm{M}$ $\mathrm{HNO}_{3}$. Bismuth concentration was measured by inductive coupled plasma atomic emission spectroscopy (ICP) by the UCLA Environmental Analysis Laboratory, and expressed as $\mu \mathrm{g} / \mathrm{g}$ wet weight for mucus bismuth concentrations or $\mu \mathrm{g} / \mathrm{l}$ for serum bismuth concentrations.

EXPERIMENTAL DESIGN - INJURY STUDIES

After an overnight fast, rats received GG311 ( $1 \mathrm{ml}$ volume) or vehicle (water) by gavage. One half hour later, the animals were treated with $60 \mathrm{mg} / \mathrm{kg}$ indomethacin ( $1 \mathrm{ml}$ volume) or vehicle (PEG 400) by subcutaneous injection. Six hours after receiving indomethacin, the animals were killed and gastric lesions were quantified.
EXPERIMENTAL DESIGN - IN VIVO MICROSCOPY STUDIES

Rats were divided into six groups, control, indomethacin, GG311, GG311+indomethacin, bismuth citrate+indomethacin, and ranitidine + indomethacin. GG311 $(100 \mathrm{mg} / \mathrm{kg}$ in $1 \mathrm{ml}$ volume), ranitidine (45 mg/kg), bismuth citrate $(57 \mathrm{mg} / \mathrm{kg}$ ) or vehicle (water) were given by gavage. One half hour later, the animals were treated with $60 \mathrm{mg} / \mathrm{kg}$ indomethacin ( $1 \mathrm{ml}$ volume) or vehicle (PEG 400) by subcutaneous injection. Two hours after the injection of indomethacin or vehicle, in vivo microscopic observation was started, with measurement of acid output, mucosal blood flow, surface cell $\mathrm{pH}_{\mathrm{i}}$, and mucus gel thickness. The chamber was superfused with $\mathrm{pH} 7 \cdot 4$ Krebs' solution for the first 30 minutes, then the superfusate was changed to $\mathrm{pH} \quad 1.0$ solution.

\section{EXPERIMENTAL DESIGN -BISMUTH}

\section{MEASUREMENTS}

Rats were treated with indomethacin, 60 $\mathrm{mg} / \mathrm{kg}$ or vehicle (PEG 400) subcutaneously, and GG311, $100 \mathrm{mg} / \mathrm{kg}$, orally as described above. Two groups were studied: GG311+ vehicle, GG311+indomethacin. Rats were killed at one, three, six, and 12 hours after GG311 treatment.

\section{SOLUTIONS}

The dye solution consisted of CF, which was first dissolved in dimethylsulphoxide and then diluted with Krebs' solution. The final concentration of the solvent was less than $1 \%$. Krebs' solution contains (in $\mathrm{mM}$ ) $136 \mathrm{NaCl}, 2.6 \mathrm{KCl}, 1.8 \mathrm{CaCl}_{2}, \mathrm{~N}-2-$ hydroxyethylpiperazine- $\mathrm{N}^{\prime}$-2-ethanesulphonic acid (HEPES) for pH 7·4. For acid superfusion, Krebs' solution was (in $\mathrm{mM}$ ) $36 \mathrm{NaCl}$, $2.6 \mathrm{KCl}, 1.8 \mathrm{CaCl}_{2}, \mathrm{HEPES}$, and titrated to $\mathrm{pH} 1.0$ with $5 \mathrm{~N} \mathrm{HCl}$. Indomethacin was dissolved in PEG 400. GG311, ranitidine, and bismuth citrate were dissolved in distilled water.

\section{CHEMICALS}

CF was purchased from Molecular Probes (Eugene, OR, USA). Indomethacin, bismuth citrate, ranitidine, and PEG400 were purchased from Sigma Chemicals (St Louis, MO, USA). Ranitidine bismuth citrate (GG311) was a gift from Glaxo Research and Development (Greenford, UK).

\section{STATISTICAL ANALYSIS}

Results were expressed as means (SEM). Comparisons between the two groups were calculated by the Student's $t$ test. Multiple group comparisons were performed by analysis of variance (ANOVA, factorial or repeated measures) followed by Fisher's contrast. A probability level $<0.05$ was considered significant. 

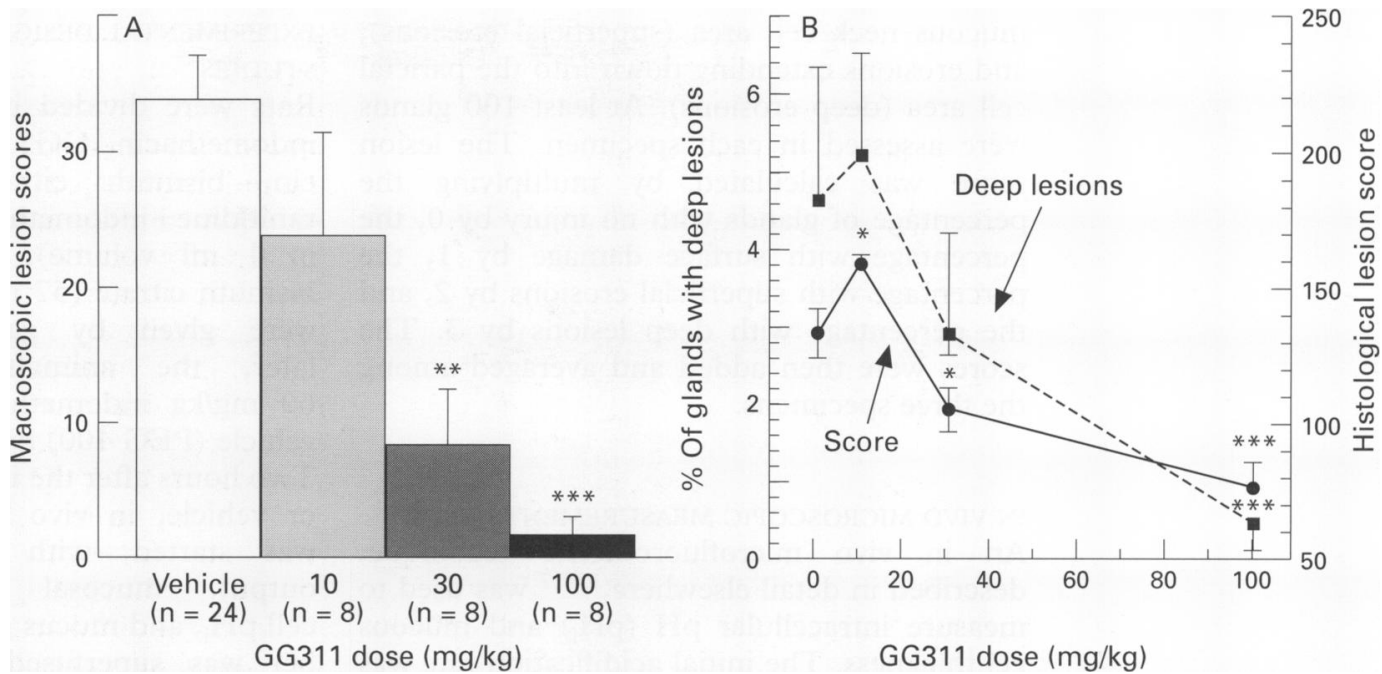

Figure 1: Inhibitory effect of GG311 on gastric damage induced by subcutaneous injection of $60 \mathrm{mg} / \mathrm{kg}$ indomethacin. Rats received GG311 or vehicle by gavage 30 minutes before indomethacin ( $60 \mathrm{mg} / \mathrm{kg}$ subcutaneous) treatment. Six hours after receiving indomethacin, gastric lesions were assessed as described in Methods. (A) Effect of GG311 on gross gastric damage. (B) Effect of GG311 on histological gastric damage. Results are the mean of rats per group. In this and subsequent figures, vertical error bars represent SEM. ${ }^{\star} p<0.05,{ }^{\star \star} p<0.01,{ }^{\star \star \star} p<0.001 \mathrm{v}$ vehicle treated rats by ANOVA.

\section{Results}

INJURY MODEL

Severe lesions were present in indomethacin injected, vehicle pre-treated rats (lesion score $=33.4$ (3.3), $n=24)$. GG311 decreased the lesion scores in a dose dependent fashion. Lesion scores were $23.5(7 \cdot 8)(n=8), 8.0(4 \cdot 4)$ $(\mathrm{n}=8)$, and $1.6(1 \cdot 1)(\mathrm{n}=8)$ in rats treated with 10,30 , and $100 \mathrm{mg} / \mathrm{kg}$ GG311, respectively (Fig 1A). Lesion scores in rats treated with the two highest doses were significantly decreased from the lesion scores in untreated rats. The histological lesion score in rats treated with indomethacin alone was $134(10)(n=8)$. Pretreatment with $10 \mathrm{mg} / \mathrm{kg}$ GG311 significantly increased the lesion score to 160 (5) $(\mathrm{n}=8)$, although pre-treatment with GG311, 30 and $100 \mathrm{mg} / \mathrm{kg}$ decreased the scores to $106(8)$ $(n=8)$ and 77 (11) $(n=8)$, respectively (Fig 1B). Deep lesions, defined as injury extending into the glandular portion of the gastric pits were significantly prevented by the highest dose $(100 \mathrm{mg} / \mathrm{kg})$ of $\mathrm{GG} 311$. Deep lesions were

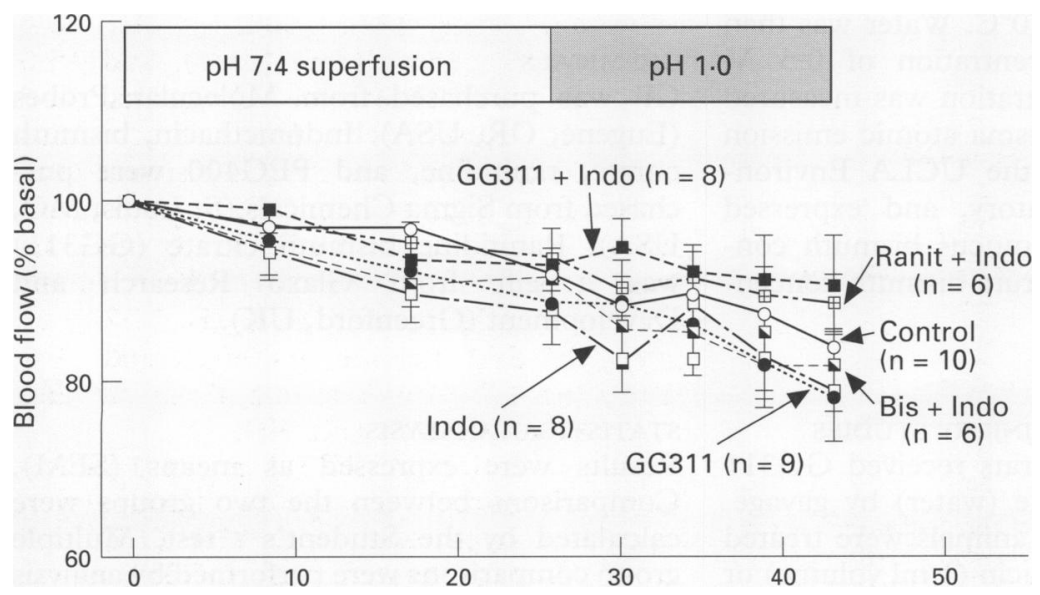

Figure 2: Effect of GG311 and its components on relative gastric mucosal blood flow. Rats were pretreated with GG311, bismuth citrate (Bis), ranitidine (Ranit) or vehicle by gavage 30 minutes before subcutaneous injection of $60 \mathrm{mg} / \mathrm{kg}$ indomethacin (Indo) or vehicle. Two hours after indomethacin or vehicle injection, gastric mucosal blood flow measurement by laser-Doppler flowmetry was started. present in $4 \cdot 7(1 \cdot 1) \%, 5 \cdot 3(1 \cdot 4) \%, 3 \cdot 0(1 \cdot 7) \%$, and $0.5(0.3) \%$, of glands in rats pretreated with $0,10,30$, and $100 \mathrm{mg} / \mathrm{kg} \mathrm{GG} 311$, respectively.

\section{IN VIVO MICROSCOPIC STUDY}

\section{Acid output}

Acid output was significantly suppressed, as expected, by GG311 or ranitidine. Acid output was $0.45(0.05) \mu \mathrm{mol} / \mathrm{min} / \mathrm{cm}^{2}$ in controls $(\mathrm{n}=10), 0.11(0.03) \mu \mathrm{mol} / \mathrm{min} / \mathrm{cm}^{2}$ in GG311 treated rats $(\mathrm{n}=9), 0.31(0.06) \mu \mathrm{mol} / \mathrm{min} / \mathrm{cm}^{2}$ in indomethacin treated rats $(n=9), 0.09$ $(0.03) \mu \mathrm{mol} / \mathrm{min} / \mathrm{cm}^{2}$ in GG311+indomethacin treated rats $(n=8), 0.39(0.06)$ $\mu \mathrm{mol} / \mathrm{min} / \mathrm{cm}^{2}$ in bismuth citrate+indomethacin treated rats $(n=6)$, and $0.13(0.03)$ $\mu \mathrm{mol} / \mathrm{min} / \mathrm{cm}^{2}$ in ranitidine + indomethacin treated rats $(n=6)$. Acid output was thus significantly decreased in groups treated with GG311 or ranitidine $(\mathrm{p}<0.05 v$ controls, by ANOVA).

\section{Mucosal blood flow}

Figure 2 depicts relative gastric mucosal blood flow. Relative gastric mucosal blood flow was not affected by any treatment during in vivo microscopic experiments. Blood flow gradually declined in all groups to a level of $83.8(1.4) \%$ $(n=10), 78 \cdot 1 \quad(4 \cdot 9) \% \quad(n=9), 79 \cdot 1 \quad(2 \cdot 5) \%$ $(n=8), 90 \cdot 8 \quad(5 \cdot 4) \% \quad(n=8), 81 \cdot 7 \quad(4 \cdot 1) \%$ $(n=6)$, and $88.8(3.3) \%(n=6)$ of baseline in control, GG311, indomethacin, GG311+ indomethacin, bismuth citrate+indomethacin, and ranitidine +indomethacin treated groups, respectively, measured at 60 minutes. Consistent with our prior studies, ${ }^{22}$ acid superfusion did not affect mucosal blood flow.

\section{Mucus gel thickness}

Figure 3 depicts mucus gel thickness, as measured by the fluorometric technique. Indomethacin significantly decreased mucus 


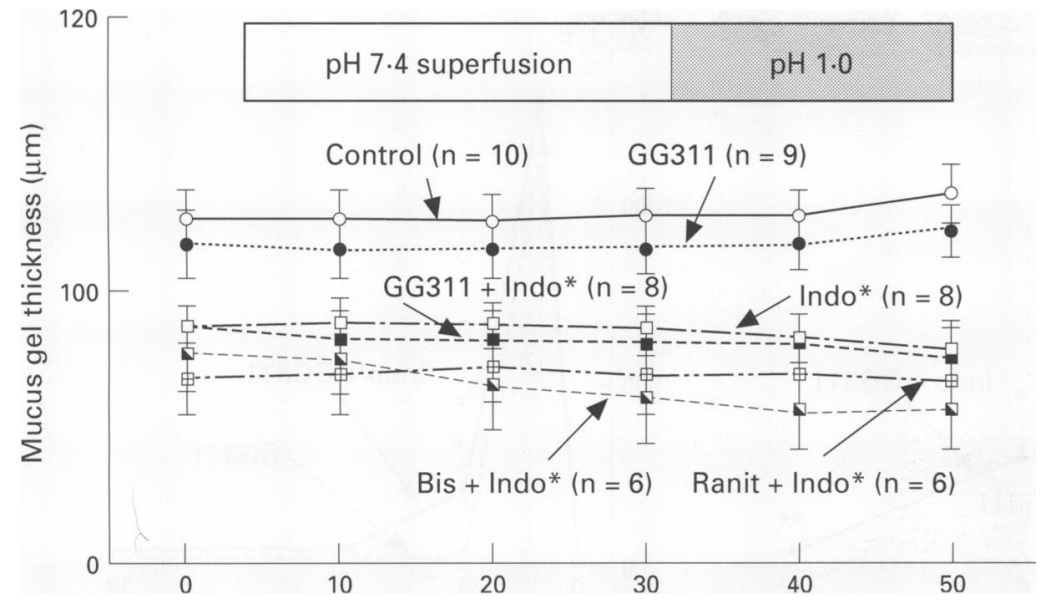

Figure 3: Effect of GG311 and its components on mucus gel thickness. Rats were pretreated with GG311, bismuth citrate (Bis), ranitidine (Ranit) or vehicle by gavage 30 minutes before subcutaneous injection of $60 \mathrm{mg} / \mathrm{kg}$ indomethacin (Indo) or vehicle. Two hours after indomethacin or vehicle injection, measurement of mucus gel thickness was started. ${ }^{\star} p<0.05 \mathrm{v}$ controls by repeated $A N O V A$.

gel thickness over the 50 minute measurement period $(\mathrm{p}<0.05 v$ control, by repeated ANOVA). At time $=0 \mathrm{~min}$, gel thickness was $119.8(5.7) \mu \mathrm{m}(\mathrm{n}=10), 112.0(4 \cdot 8) \mu \mathrm{m}$ $(\mathrm{n}=9), 90 \cdot 0(5 \cdot 0) \mu \mathrm{m}(\mathrm{n}=9), 88.2(5 \cdot 6) \mu \mathrm{m}$ $(\mathrm{n}=8), 78 \cdot 4(7 \cdot 3) \mathrm{mm}(\mathrm{n}=6)$, and $83.5(6 \cdot 1)$ $\mathrm{mm}(\mathrm{n}=6)$ in the control, GG311, indomethacin, GG311+indomethacin, bismuth citrate+indomethacin, and ranitidine+indomethacin treated groups, respectively. GG311 pretreatment did not affect gel thickness of the control or indomethacin pre-treated groups. In accord with our prior studies, ${ }^{22}$ acid superfusion had no effect on gel thickness.

Intracellular $\mathrm{pH}$ and initial acidification rate During superfusion with $\mathrm{pH} 7 \cdot 4$ Krebs' buffer, $\mathrm{pH}_{\mathrm{i}}$ remained stable in the range of $6.98(0.06)$ to $7 \cdot 11(0 \cdot 04)$, with no statistical differences between any of the groups. During superfusion with $\mathrm{pH} 1.0$ buffer, $\mathrm{pH}_{\mathrm{i}}$ was significantly lower in the indomethacin and ranitidine+indomethacin groups than in the control group

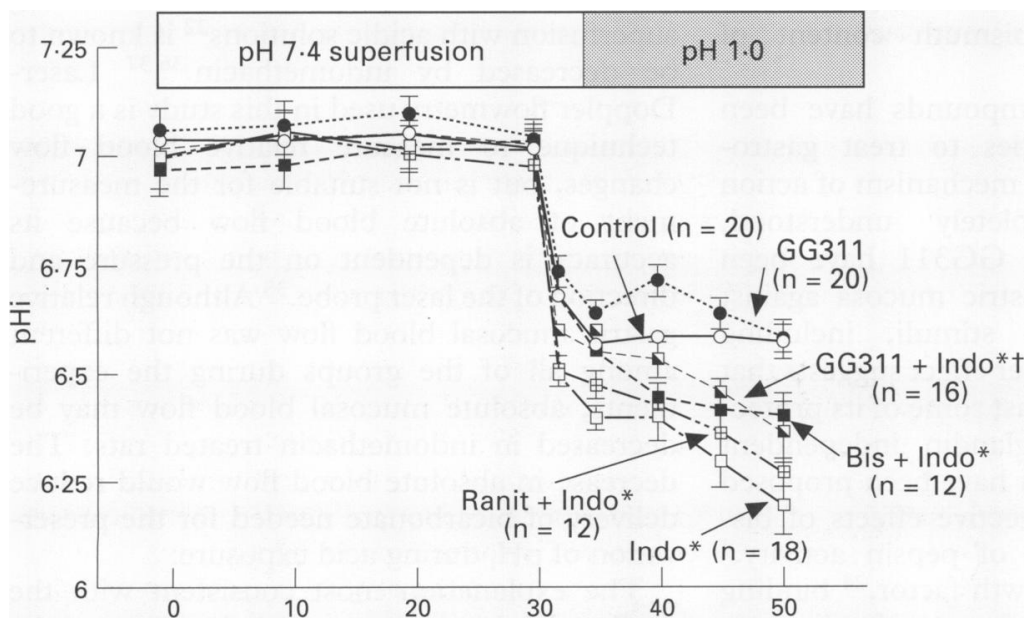

Figure 4: Effect of GG311 and its components on intracellular $p H\left(p H_{i}\right)$ of gastric surface cells. Rats were pretreated with GG311, bismuth citrate (Bis), ranitidine (Ranit) or vehicle by gavage 30 minutes before subcutaneous injection of $60 \mathrm{mg} / \mathrm{kg}$ indomethacin (Indo) or vehicle. Two hours after indomethacin or vehicle injection, gastric $p H_{i}$ measurement was started. Intracellular $p H$ was compared among six groups both during superfusion with $p H 7.4$ and $p H 1.0$ solutions by repeated ANOVA. ${ }^{\star} p<0.05 \mathrm{v}$ controls, $t p<0.05 \mathrm{v}$ indomethacin treated group by repeated $A N O V A$ for the period of acid superfusion (20-50 min, inclusive). $(\mathrm{p}<0.05$, by repeated ANOVA during acid superfusion), and was significantly higher in the GG311+indomethacin, and bismuth citrate +indomethacin groups compared with the indomethacin group $(p<0.05$, by repeated ANOVA during acid superfusion). GG311 itself had no significant effect on $\mathrm{pH}_{\mathrm{i}}$ during acid superfusion in the absence of indomethacin (Fig 4).

The initial acidification rate was calculated from the initial drop of $\mathrm{pH}_{\mathrm{i}}$ after the superfusion of $\mathrm{pH} 1.0$ buffer. Initial acidification rate was $7.53(0.53) \mathrm{mM} / \mathrm{min}(\mathrm{n}=20), 6.63$ $(0.54) \quad \mathrm{mM} / \mathrm{min} \quad(\mathrm{n}=20), \quad 11.75 \quad(0.55)$ $\mathrm{mM} / \mathrm{min} \quad(\mathrm{n}=18), 8.08 \quad(0.54) \quad \mathrm{mM} / \mathrm{min}$ $(\mathrm{n}=16), 9.32(0.98) \mathrm{mM} / \mathrm{min}(\mathrm{n}=12)$, and $10.34(0.94) \mathrm{mM} / \mathrm{min}(\mathrm{n}=12)$ in the control, GG311, indomethacin, GG311+indomethacin, bismuth citrate+indomethacin, and ranitidine+indomethacin treated groups, respectively. The acidification rates in the GG311, GG311 + indomethacin, and bismuth citrate +indomethacin groups were statistically similar to that of the controls, and was significantly faster in the indomethacin, and ranitidine+indomethacin groups $(p<0.05$ $v$ control, by ANOVA).

\section{MUCUS BISMUTH CONCENTRATIONS}

Figure 5 shows mucus bismuth concentration in rats treated with either GG311 alone or GG311 plus indomethacin. Bismuth concentrations in the gastric mucus was $7 \cdot 3(2 \cdot 8) \mu \mathrm{g} / \mathrm{g}$ wet weight $(n=5)$ at baseline. In rats treated with GG311 alone, gastric mucus bismuth concentrations were 4903 (2519) $(n=4)$, $149.6(53.5)(n=5), 40.8(12 \cdot 2)(n=6)$, and $31.9(14.3) \mu \mathrm{g} / \mathrm{g}(\mathrm{n}=3)$ at one, three, six, and 12 hours, respectively. Indomethacin increased the bismuth concentration in GG311 treated rats to $6944(1596)(n=4, N S), 2017$ (456) $(n=5,13 \cdot 5$-fold increase, $p<0.01), 1788$ (669) $(n=6,49 \cdot 4$-fold increase, $p<0.05)$, and $207 \cdot 3(20 \cdot 2)(n=3,6 \cdot 5$-fold increase, $p<0.01)$ $\mu \mathrm{g} / \mathrm{g}$ at one, three, six, and 12 hours, respectively (Fig 5A). Bismuth concentrations in the duodenal mucus was $12.8(8.5) \mu \mathrm{g} / \mathrm{g}$ wet weight $(n=5)$ at baseline. In rats treated with GG311 alone, duodenal mucus bismuth concentrations were $1133(608)(n=4), 16.6$ $(12 \cdot 1)(n=5), 15.6(10.5)(n=6)$, and 15.0 $(5 \cdot 4) \mu \mathrm{g} / \mathrm{g} \quad(\mathrm{n}=3)$ at one, three, six, and 12 hours, respectively. Indomethacin also increased the duodenal mucus bismuth concentration to a lesser extent. Bismuth concentrations in indomethacin + GG311 treated rats were 1296 (687) ( $n=4, N S), 208.9(66.9)$ $(\mathrm{n}=5,12 \cdot 5$-fold increase, $\mathrm{p}<0 \cdot 05), 51 \cdot 2(7 \cdot 6)$ $(n=6,3 \cdot 2$-fold increase, $p<0.05)$, and 29.7 $(12.9)(n=3, N S) \mu g / g$ at one, three, six, and 12 hours, respectively (Fig $5 \mathrm{~B}$ ).

Administration of GG311 resulted in low levels of bismuth absorption. Basal serum bismuth concentration was $14.0(7 \cdot 0) \mu \mathrm{g} / \mathrm{l}$ $(n=4)$. In rats treated with GG311 alone, serum bismuth concentrations were 68.0 $(32 \cdot 3)(n=3), 173.3(115 \cdot 7)(n=3)$, and 112.9 $(44 \cdot 8)(\mathrm{n}=3) \mu \mathrm{g} / \mathrm{l}$ at three, six, and 12 hours, respectively. In indomethacin + GG311 treated 

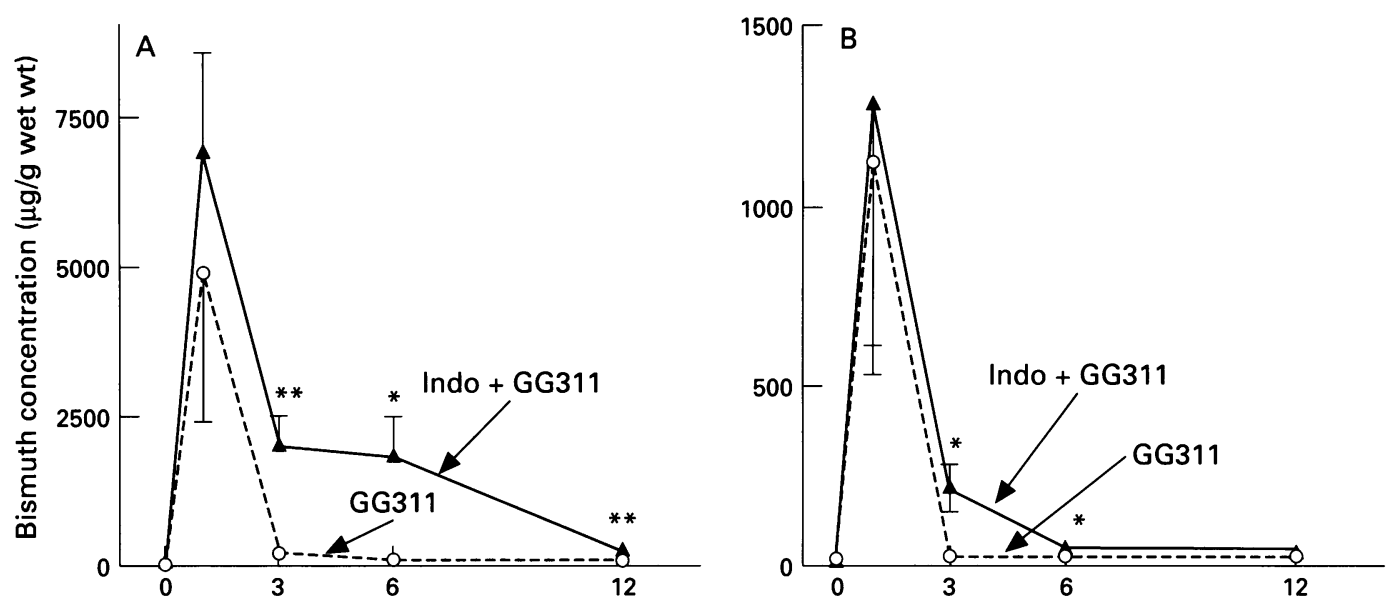

Figure 5: Bismuth concentration in gastroduodenal mucus gel. Rats were pretreated with GG311 by gavage 30 minutes before subcutaneous injection of $60 \mathrm{mg} / \mathrm{kg}$ indomethacin (Indo) or vehicle. Rats were killed at one, three, six, and 12 hours after GG311 treatment. Bismuth concentration was measured by inductive coupled plasma atomic emission spectroscopy as described in Methods. (A) Bismuth concentration in gastric mucus gel. (B) Bismuth concentration in duodenal mucus gel. ${ }^{\star} p<0.05,{ }^{\star \star} p<0.01 \mathrm{v}$ rats treated with $G G 311$ alone by the Student's t test.

rats, serum bismuth concentrations were $97 \cdot 8$ $(35 \cdot 3)(n=3), 84 \cdot 9(25 \cdot 1)(n=3)$, and $37 \cdot 3$ $(7 \cdot 1) \mu \mathrm{g} / \mathrm{l}(\mathrm{n}=3)$ at three, six, and 12 hours, respectively. There was no statistically significant difference between the two groups.

\section{Discussion}

GG311 dose dependently prevented severe mucosal lesions in indomethacin treated rats and prevented microscopic injury at the 30 and $100 \mathrm{mg} / \mathrm{kg}$ doses, and prevented deep injury to the gastric glands at the $100 \mathrm{mg} / \mathrm{kg}$ dose. GG311 (100 mg/kg) significantly suppressed acid output. No treatment affected relative mucosal blood flow. Indomethacin significantly reduced mucus gel thickness, increased the initial acidification rate, and impaired $\mathrm{pH}_{\mathrm{i}}$ homeostasis during luminal acid superfusion. In indomethacin treated rats, GG311 (100 $\mathrm{mg} / \mathrm{kg}$ ) normalised the initial acidification rate to control values without affecting gel thickness, and improved $\mathrm{pH}_{\mathrm{i}}$ homeostasis during acid superfusion. The most striking and novel finding was that indomethacin substantially increased at times >one hour the gastric and duodenal mucus gel bismuth content of GG311 treated rats.

Although bismuth compounds have been used for several centuries to treat gastrointestinal problems, their mechanism of action has remained incompletely understood. Bismuth salts including GG311 have been shown to protect the gastric mucosa against a variety of injurious stimuli, including NSAIDs. 128923 This latter effect suggests that bismuth might exert at least some of its protective effect in a prostaglandin independent fashion. Mechanisms that have been proposed to explain the gastroprotective effects of bismuth include inhibition of pepsin activity, ${ }^{4}$ binding of epidermal growth factor, ${ }^{24}$ binding to ulcers, ${ }^{25}$ stimulation of prostaglandin synthesis and bicarbonate secretion, ${ }^{26} 27$ antibacterial activity, ${ }^{28}$ and binding to mucus. ${ }^{29}$ Antisecretory compounds such as the $\mathrm{H}_{2}$ receptor antagonist ranitidine have also been shown to protect the stomach against injury. ${ }^{30}$ The primary protective action of $\mathrm{H}_{2}$ receptor antagonists presumably stems from their antisecretory effect, and not from an enhancement of gastroprotective factors.

In this study, indomethacin reduced mucus gel thickness and impaired $\mathrm{pH}_{\mathrm{i}}$ homeostasis during acid exposure. The mucus gel layer covering the epithelial surfaces of gastric mucosa constitutes the first line of mucosal defence against luminal acid. The thinned mucus gel in indomethacin treated rats is either caused by diminished mucus synthesis or increased degradation. In previous studies, indomethacin thinned the adherent mucus gel, and decreased the synthetic rate of gastric mucus ${ }^{3132}$ rendering the first possibility plausible. On the other hand, it has been shown that gastric mucus content is increased after fasting, which is assumed to be due to the decreased mechanical abrasion of the gastric mucosa. ${ }^{33}$ Therefore, it is also possible that gastric hypercontraction, which is a known effect of ulcerogenic doses of indomethacin, ${ }^{34} 35$ may increase the degradation of the gastric mucus resulting in the thinned mucus gel. Gastric mucosal blood flow, which has been shown to affect $\mathrm{pH}_{\mathrm{i}}$ homeostasis during superfusion with acidic solutions ${ }^{22}$ is known to be decreased by indomethacin. ${ }^{36} 37$ LaserDoppler flowmetry used in this study is a good technique to measure relative blood flow changes, but is not suitable for the measurement of absolute blood flow because its accuracy is dependent on the pressure and direction of the laser probe. ${ }^{38}$ Although relative gastric mucosal blood flow was not different among all of the groups during the experiments, absolute mucosal blood flow may be decreased in indomethacin treated rats. The decrease in absolute blood flow would reduce delivery of bicarbonate needed for the preservation of $\mathrm{pH}_{\mathrm{i}}$ during acid exposure.

The explanation most consistent with the finding that bismuth compounds protected the stomach from indomethacin associated injury is that bismuth, present in high concentrations in the gastric mucus gel, decreased its acid permeability. This impaired permeability was manifest as a slowed acidification rate and improved $\mathrm{pH}_{\mathrm{i}}$ homeostasis during acid 
superfusion, compared with rats treated with indomethacin alone. We assume that the rate of rapid, initial drop of $\mathrm{pH}_{\mathrm{i}}$ (initial acidification rate) is primarily dependent on the rate of acid permeation through the mucus gel. We have previously shown that the initial acidification rate is inversely correlated to mucus gel thickness - that is, the thicker the gel, the slower the diffusion. ${ }^{39}$ Other homeostatic mechanisms that change $\mathrm{pH}_{\mathrm{i}}$ such as increased $\mathrm{Na}^{+} / \mathrm{H}^{+}$ exchange are induced relatively slowly, and thus would have little effect on the initial drop in $\mathrm{pH}_{\mathrm{i}} \cdot{ }^{4041}$ Although GG311 decreased acid secretion, luminal $\mathrm{pH}$ was held constant by the high flow rate of the superfusate. Furthermore, the small change in acid secretory state of the mucosa - that is, from basal to fully inhibited was unlikely to change $\mathrm{pH}_{\mathrm{i}}$ regulation, as we have shown previously in cimetidine treated rats, ${ }^{22}$ and also in this study in the ranitidine only group. On the basis of the foregoing considerations, the most plausible explanation for the normal acidification rate despite a thinned mucus gel in the indomethacin+ GG311 group is decreased proton permeability of the adherent mucus gel.

The mechanism for the decreased permeability of adherent gastric mucus in the presence of NSAIDs, and high concentration of bismuth, however, is unclear. Indomethacin, if anything, increased mucus proton permeability in and of itself, as the increase in initial acidification rate $(56 \%)$ in indomethacin treated rats was greater than would have been predicted from the $19 \%$ fall in gel thickness. * The initial acidification rate in the GG311 group was unchanged from control rats, suggesting that GG311 alone had no measurable effect on mucus proton permeability. Thus, high mucus bismuth concentrations, found only in the indomethacin+GG311 group at three hour time point, correlated with decreased proton permeability of adherent gastric mucus. This suggests a direct, probably physical interaction between bismuth and the mucus gel. The nature of this interaction is not clear, although there is experimental evidence suggesting that divalent cations such as $\mathrm{Mg}^{2+}$, $\mathrm{Ca}^{2+}$, and $\mathrm{Fe}^{2+}$ can alter the physical properties of adherent mucus. ${ }^{42-44}$ Moreover, Lee found that precipitated gastric mucus glycoprotein complexed with colloidal bismuth subcitrate in vitro produced a mucus-bismuth complex that impeded proton permeability. ${ }^{45}$ These in vitro experiments thus provide a plausible basis for hypothesis that bismuth, in high concentrations, changes the physical structure of adherent gastric mucus so as to decrease its permeability to protons.

The reason why indomethacin increased gastric mucus bismuth concentrations by the substantial extent observed is also not obvious. One possibility is that bismuth might be adhering to damaged areas or an inflammatory exudate in the gastric mucosa. Indeed, it

*Our previous data demonstrated that the per cent change in initial acidification rate was $68 \%$ of the per cent change in mucus gel thickness. We would thus predict that for a $19 \%$ decrease in mucus gel thickness, initial acidification rate would increase by only $13 \%$. has been shown that bismuth binds to injured gastric mucosa in a human study ${ }^{45}$ and experimental ulcer models. ${ }^{25}$ In this study, however, severe and histological injury were nearly absent under the conditions in which mucus bismuth concentrations were studied. Recently, several reports have suggested that the pathogenesis of indomethacin induced gastric injury involves gastric hypercontraction and microvascular disturbance in addition to a prostaglandin deficiency. ${ }^{34} 354647$ Takeuchi et $a l^{46}{ }^{47}$ reported that an ulcerogenic dose of indomethacin induced a pronounced increase in frequency and amplitude of gastric contractions, which was associated with oscillatory fluctuations of mucosal blood flow, and increased extravasation of Evans blue dye. These findings occurred prior to the appearance of gastric lesions. Therefore, it is plausible that bismuth was bound to an exudate derived from microvessels before the appearance of gastric lesions. The second prospect is that indomethacin slowed gastric emptying, allowing more contact time between GG311 and the gastric mucosa. This latter hypothesis is not supported by experimental motility studies, which suggest that gastric emptying, if changed at all, is hastened by indomethacin. ${ }^{4849}$ Furthermore, gastric hypercontraction induced by indomethacin may enhance the mechanical contact between GG311 and the gastric mucosa, increasing the diffusion of bismuth particles into the gastric mucus gel. Another explanation is that indomethacin changed the chemical composition of the gastric mucus gel in such a manner as to increase binding to cationic metals. For example, indomethacin decreased the amount of lipids in rat gastric mucus. ${ }^{50}$ The NSAID aspirin also decreased the density of phospholipids and the hydrophobicity of canine gastric mucus. ${ }^{5152}$ Indomethacin, by decreasing the hydrophobicity and lipid content of the surface of the adherent mucus, may have increased the accessibility of the mucus to exogenous bismuth. The studies with bismuth citrate and ranitidine alone strongly suggest that the bismuth, and not the ranitidine component of GG311 decreases the permeability of gastric mucus.

The potentiation of bismuth concentrations in the gastric mucus by indomethacin has significance beyond the observed alterations of acid permeability and protection against indomethacin induced gastric mucosal injury. Helicobacter pylori, the organism associated with chronic gastritis and recurrent peptic ulcer disease, resides in the juxtamucosal region of the gastric mucus. This organism is sensitive to bismuth in vitro, ${ }^{53}$ although clinical trials in which bismuth compounds were used as monotherapy to eradicate $H$ pylori have been disappointing. ${ }^{54} 55$ Furthermore, $H$ pylor infection is associated with decreased gastric mucus bismuth concentrations in human postmortem specimens treated in vitro with colloidal bismuth subcitrate. ${ }^{21}$ This study suggests that the combination of a bismuth containing compound such as GG311 combined with an NSAID such as indomethacin, 
by virtue of its high and prolonged concentration of bismuth in mucus, might be a logical combination for the large scale eradication of $H$ pylori in selected clinical populations.

In conclusion, this study indicates that bismuth concentrations in the gastric mucus are increased during the inapparent gastric injury induced by indomethacin, and are associated with impaired acid permeability of the mucus gel. Thus, GG311 protects gastric mucosa from indomethacin induced injury by strengthening pre-epithelial defence mechanisms in addition to inhibiting acid secretion. As gastroprotective properties of bismuth compounds may also result from inhibition of pepsin activity, binding of bile acids and epidermal growth factor, and induction of PG synthesis, and because bismuth compounds also protect the gastric mucosa from other noxious stimuli such as ethanol and cold restraint stress, ${ }^{2} 23$ it is possible that other mechanisms may also be involved in the gastroprotective effect of GG311.

We would like to thank Mr Larry Myers and Mr Jerry Snidow of the Glaxo Research Institute for their helpful suggestions and advice concerning the design of these experiments.

This work was supported by a Veterans Administration Merit Review Award (JDK), the Glaxo Research Institute (JDK), the CURE Experimental Ulcer and Blood Flow Core of NIH DK41301 (PHG), and a CURE Pilot and Feasibility Award (JDK).

1 Konturek SJ, Kwiecien N, Obtulowicz W, Hebzda Z, Oleksy J. Effects of colloidal bismuth subcitrate on aspirin-induced gastric microbleeding, DNA loss, and prostaglandin formation in humans. Scand $¥$ Gastroenterol prostaglandin forma

2 Goldenberg MM, Honkomp LJ, Burrous SE, Castellon AW. Protective effect of Pepto-Bismol liquid on the gastric mucosa of rats. Gastroenterology 1975; 69: 636-40.

3 Slomiany BL, Nishikawa H, Bilski J, Slomiany A. Colloidal bismuth subcitrate inhibits peptic degradation of gastric mucus and epidermal growth factor in vitro. $A m \mathcal{F}$ Gastroenterol 1990; 85: 390-3.

4 Tay HP, Chaparala RC, Harmon JW, Huesken J, Saini N, Hakki FZ, et al. Bismuth subsalicylate reduces peptic injury of the oesophagus in rabbits. Gut 1990; 31: $11-6$.

5 Shorrock CJ, Crampton JR, Gibbons LC, Rees WDW. Effect of bismuth subcitrate on amphibian gastroduodenal bicarbonate secretion. Gut 1989; 30: 917-21.

6 Ehsanullah R, Page M, Tildesley G, Wood J. Prevention of gastroduodenal damage induced by non-steroidal antiinflammatory drugs: controlled trial of ranitidine. $B M \mathcal{F}$ 1988; 297: 1017-21.

7 Robinson MG, Griffin JWJ, Bowers J, Kogan FJ, Kogut DG, Lanza FL, et al. Effect of ranitidine on gastroduodenal mucosal damage induced by nonsteroidal antiinflammatory drugs. Dig Dis Sci 1989; 34: 424-8.

8 Stables R, Campbell CJ, Clayton NM, Clitherow JW, Grinham CJ, McColm AA, et al. Gastric anti-secretory, mucosal protective, anti-pepsin, and anti-helicobacter properties of ranitidine bismuth citrate. Aliment Pharmacol Ther 1993; 7: 237-46.

9 Hudson N, Murray FE, Cole AT, Turnbull GM, Lettis GM, Hawkey CJ. Ranitidine bismuth citrate and aspirininduced gastric mucosal injury. Aliment Pharmacol Ther 1993; 7: 515-21.

10 Djahanguiri $B$. The production of acute gastric ulceration by indomethacin in the rat. Scand $\mathcal{F}$ Gastroenterol 1969; 4: 265-7.

11 Satoh H, Guth PH, Grossman MI. Role of food in gastrointestinal ulceration produced by indomethacin in the rat. Gastroenterology 1982; 83: 210-5.

12 Itoh M, Paulsen G, Guth PH. Hemorrhagic shock and acid gastric injury in the rat Gastroenterology 1986; 90 1103-10.

13 Kaneko K, Guth PH, Kaunitz JD. In vivo measurement of rat gastric surface cell intracellular pH. Am $\mathcal{f}$ Physiol 1991; 261: G548-52.

14 Kaunitz JD, Nishizaki Y, Kaneko K, Guth PH. Effect of orogastric nicotine on rat gastric mucosal gel thickness, surface cell viability, and in

15 Nishizaki Y, Guth PH, Kaunitz JD. Isoproterenol enhances rat gastric mucosal barrier function in vivo. Gastroenterology 1993; 105: 340-6.

16 Nishizaki Y, Guth PH, Quintero E, Del Rivero M, Bover J, Kaunitz JD. Prostaglandin $\mathrm{E}_{2}$ enhances gastric defense mechanisms against acid injury in uremic rats. Gastroenterology 1994; 107: 1382-9.

17 Tanaka S, Kaunitz JD. Indomethacin does not alter the effect of pentagastrin on rat gastric defense mechanisms. Peptides 1996; 17: 155-9.

18 Garner A, Heylings JR. Stimulation of alkaline secretion in amphibian-isolated gastric mucosa by 16,16-dimethyl

19 Kerss S, Allen A, Garner A. A simple method for measuring thickness of the mucus gel layer adherent to rat, frog, and human gastric mucosa: influence of feeding, prostaglandin, $N$-acetylcysteine and other agents. Clin Sci prostaglandin, $N$-a

20 Slikkerveer A, Helmich RB, de Wolff FA. Analysis for bismuth in tissue by electrothermal atomic absorption spectrometry. Clin Chem 1993; 39: 800-3.

$21 \mathrm{Muñoz} \mathrm{DJB,} \mathrm{Tasman-Jones} \mathrm{C,} \mathrm{Pybus} \mathrm{J.} \mathrm{Effect} \mathrm{of}$ Helicobacter pylori on colloidal bismuth subcitrate concentration in gastric mucus. Gut 1994; 33: 592-6.

22 Nishizaki Y, Guth PH, Kim G, Wayland H, Kaunitz JD. Pentagastrin enhances gastric mucosal defenses in vivo: luminal acid-dependent and independent effects. $A m \mathscr{f}$ Physiol 1994; 267: G94-104.

23 Goldenberg MM, Honkomp LJ, Castellion AW. Prevention of bismuth subsalicylate of gastric mucosal lesions in response to noxious stimuli in rats. Pharmacol Res Comm 1978; 10: 13-20.

24 Slomiany BL, Nishikawa H, Bilski J, Slomiany A. Colloidal bismuth subcitrate inhibits peptic degradation of gastric mucus and epidermal growth factor in vitro. $A m \mathcal{f}$ Gastroenterol 1990; 85: 390-3.

25 Koo J, Ho J, Lam SK, Wong J, Ong GB. Selective coating of gastric ulcer by tripotassium dicitrato bismuthate in the rat. Gastroenterology 1982; 82: 864-70.

26 Konturek SJ, Bilski J, Kwiecien N, Obtulowicz W, Kopp B, Oleksy J. De-Nol stimulates gastric and duodenal alkaline secretion through prostaglandin dependent mechanism. Gut 1987; 28: 1557-63.

27 Mertz-Nielsen A, Steenberg P, Neumark T, Bukhave K, Rask-Madsen J. Colloidal bismuth subcitrate causes sustained release of gastric mucosal prostaglandin E2. Aliment Pharmacol Ther 1991; 5: 127-33.

28 Manhart MD. In vitro antimicrobial activity of bismuth subsalicylate and other bismuth salts. Rev Infect Dis 1990; 12: S11-5.

29 Lambert JR. Pharmacology of bismuth-containing compounds. Rev Infect Dis 1991; 13 (suppl 8): S691-5

30 Navarova J, Nasalova V. Effect of $\mathrm{H} 2$-receptor antagonists on indomethacin-induced lysosomal enzyme release from rat gastric mucosa. Methods Find Exp Clin Pharmacol 1994; 16: 119-24.

31 Torii A, Kameda H, Kawamura T, Onizawa N, Nozawa H, Ariizumi $M$, et al. Effect of gastric mucus on the uptake of the carcinogen MNNG by gastric mucosal DNA. $f$ Clin Gastroenterol 1990; 12 (suppl 1): S1 16-24.

32 Slomiany BL, Piotrowski J, Ismail A, Rajiyah G, Tamura S, Bielanski W, et al. Protection against alcohol-induced gastric mucosal injury by nitecapone. Gen Pharmacol 1991; 22: 1055-62.

33 Ohara S, Hotta K. Effects of fasting on mucus glycoprotein biosynthesis in rat stomach. Comp Biochem Physiol 1985; 82B: $207-10$

34 Mersereau WA, Hinchey EJ. Relationship between the gastric myoelectric and mechanical activity in the genesis of ulcers in indomethacin-insulin-treated rats. Dig Dis $S c i$ 1988; 33: 200-8.

35 Ueki S, Takeuchi K, Okabe S. Gastric motility is an important factor in the pathogenesis of indomethacin-induced gastric mucosal lesions in rats. Dig Dis Sci 1988; 33: 209-16.

36 Gerkens JF, Shand DG, Flexner C, Nies AS, Oates JA, Data JL. Effect of indomethacin and aspirin on gastric blood flow and acid secretion. I Pharmacol Exp Ther 1977; 203: 646-52.

37 Holm L, Jägare A. Role of prostaglandins in regulation of gastric mucosal blood flow and acid secretion. $\mathrm{Am} \mathcal{F}$ Physiol 1992; 263: G446-51.

38 Kiel JW, Riedel GL, DiResta GR, Shepherd AP. Gastric mucosal blood flow measured by laser-Doppler velocimetry. Am F Physiol 1985; 249: G539-45.

39 Engel E, Guth PH, Nishizaki Y, Kasunitz JD. Barrier function of the gastric mucus gel. Am $\mathcal{f}$ Physiol 1995; 269: G994-9.

40 Kaneko K, Guth PH, Kaunitz JD NA+/H+ exchange regulates intracellular $\mathrm{pH}$ of rat gastric cells in vivo. Pflugers Arch 1992; 421: 322-8.

41 Seidler U, Carter K, Ito S, Silen W. Effect of $\mathrm{CO} 2$ on $\mathrm{pHi}$ in rabbit parietal, chief, and surface cells. Am $\mathcal{f}$ Physiol 1989; 256: G466-75.

42 Crowther RS, Marriott C, James SL. Cation induced changes in the rheological properties of purified mucus glycoproteins. Biorheology 1984; 21: 253-63.

43 Forstner JF, Jabbal I, Findlay BP, Forstner GG. Interaction of mucins with calcium, $\mathrm{H}^{+}$ion and albumin. Mod Probl Pediatr 1976; 19: 54-65.

44 Marriot C, Shih CK, Litt M. Changes in the gel properties of tracheal mucus induced by divalent cations. Biorheology 1979; 16: 331-7.

45 Lee SP. A potential mechanism of action of colloidal bismuth subcitrate: diffusion barrier to hydrochloric acid. Scand $\mathcal{F}$ Gastroenterol 1982; 17 (suppl 80): 17-21.

46 Takeuchi K, Ueshima K, Hironaka Y, Fujioka Y, Matsumoto $\mathrm{J}$, Okabe S. Oxygen free radicals and lipid peroxidation in the pathogenesis of gastric mucosal lesions induced by indomethacin in rats. Digestion 1991; 49: 175-84. 
47 Takeuchi K, Ueki S, Okabe S. Importance of gastric motility in the pathogenesis of indomethacin-induced gastric lesions in rats. Dig Dis Sci 1986; 31: 1114-22.

48 Stein J, Zeuzem S, Uphoff $K$, Laube $H$. Effects of prostaglandins and indomethacin on gastric emptying in the rat. Prostaglandins 1994; 47: 31-40.

49 Kohut A, Majzis J. Effect of allopurinol and superoxide dismutase on indomethacin-induced gastric lesions in the mutase on indomethacin-induced
rat. Physiol Res 1993; 42: 273-6.

50 Slomiany A, Mizuta K, Piotrowski J, Nishikawa $H$ Slomiany BL Gastric , Piotrowski J, Nishika Slomiany BL. Gastric mucosal; protection by sucralfate involves phosphoinositides participation. Int $\mathcal{F}$ Biochem

1 Goddard PJ, Kao Y-CJ, Lichtenberger L. Luminal surface hydrophobicity of canine gastric mucosa is dependent on a surface mucous gel. Gastroenterology 1990; 98: 361-70.

52 Kao Y-C, Goddard PJ, Lichtenberger LM. Morphological effects of aspirin and prostaglandin on the canine gastric mucosal surface. Gastroenterology 1990; 98: 592-606.

53 McNulty CAM, Dent J, Wise R. Susceptibility of clinical isolates of Campylobacter pyloridis to 11 antimicrobial agents. Antimicrob Agents Chemother 1985; 28: 837-8.

54 Rauws EAJ, Tytgat GN. Campylobacter pylori: treatment of gastritis. In: Rathbone BJ, Heatley RV, ed.
of of gastritis. In: Rathbone BJ, Heatley RV, ed. Campylobacter pylori and gastrointestinal disease. Oxford:

55 Coghlan JG, Tobin A, O'Morian C. Campylobacter pylori and ulcer treatment. In: Rathbone BJ, Heatley RV, ed. Campylobacter pylori and gastroduodenal disease. Oxford: Blackwell Scientific, 1989: 232-45. 